\title{
A Rare Complication of Cardiopulmonary Resuscitation: Liver Injury
}

\author{
Kardiyopulmoner Resüsitasyonun Nadir Bir Komplikasyonu: Karaciğer Yaralanması
}

\author{
Eyyüp Yılmaz', Mehmet Özbay², Elif Ömeroğlu², Nezih Anolay², Hüseyin Sarı², Mustafa İçer ${ }^{3}$ \\ 'The Council of Forensic Medicine, Diyarbakır Regional Center, Diyarbakı, Turkey \\ ${ }^{2}$ The Council of Forensic Medicine, The Ministry of Justice, Istanbul, Turkey \\ ${ }^{3}$ Department of Emergency Medicine, Faculty of Medicine, Dicle University, Diyarbakır,Turkey
}

\section{ABSTRACT}

Introduction: Cardiopulmonary resuscitation (CPR) is a medical process that could be life-saving, but it may also bring about lots of medical complications with regard to CPR. In this case study, we report a legal case with a ruptured liver found at the autopsy.

Case Report: A 37-year-old woman, who had angina on her chest formerly, was taken to the hospital in the emergency medicine room as a death. As soon as she arrived there, CPR was applied. Unfortunately, there was no response. After performing the autopsy of her corpse, sternum bone fracture, excessive accumulation of hemorrhage into the abdomen, and liver rupture were discovered.

Conclusion: Inappropriate chest compression may cause liver injury during mechanical CPR processes.

Keywords: CPR, liver injury, emergency, autopsy

Received: 18.05.2013 Accepted: 26.08.2013

\section{ÖZET}

Giriş: Kardiyopulmoner resüsitasyon (KPR) hayat kurtarabilen ancak sonrasında pek çok komplikasyon gelişebilen bir uygulamadır. Bu olgu çalışmasında, otopside KPR'ye bağlı karaciğer yaralanması tanısı konulan bir adli olgu sunulmuştur.

Olgu Sunumu: Daha önce göğüs ağıısı olan 37 yaşında bayan hastane acil servisine arrest olarak getirilmiş ve uygulanan KPR işlemine yanıt alınamamıştır. Yapılan otopsisinde sternumda fraktür, abdomende aşırı kan birikimi ve karaciğer yaralanması saptanmıştır.

Sonuç: Uygun yapılmayan göğüs kompresyonları karaciğer yaralanması yapabilir.

Anahtar Kelimeler: KPR, karaciğer yaralanması, acil, otops

Geliş Tarihi: 18.05.2013 Kabul Tarihi: 26.08.2013

\section{Giriş}

Kardiyopulmoner resüsitasyon (KPR) kardiyak arrest sonrasında sağ kalımı arttıran bir takım hayat kurtarıcı girişimlerden oluşur. Hava yolu açıklığı, solunum desteğinin sağlanması ve göğüs kompresyonu KPR' nin temel yapı taşlarını oluşturur. Artık günümüzde göğüs kompresyonun etkinliğinin daha fazla olduğu görülmüş olup, KPR uygulamalarında hava yolu açıklığı ve solunum desteğinin sağlanmasından önce yer aldığı görülmektedir (1). Ancak göğüs kompresyonuna bağlı pek çok komplikasyon gelişebilmektedir (2).

Bu çalışmada acil servise arrest olarak getirilen, KPR sonrası eksitus olan ve yapılan adli otopside batın içerisinde kan koleksiyonu ile karaciğer yaralanması saptanan bir olgu sunulmuştur.

\section{Olgu Sunumu}

Özgeçmişinde bilinen bir hastalığı ve ilaç kullanım öyküsü olmayan otuz yedi yaşında bayan hasta, göğüs ağıısı başladıktan 6 saat sonra şuuru kapalı olarak evde bulunmuş. Ailesi tarafından özel araçları ile acil servise getirilmiş. Hastanın acil servisteki muayenesinde şuuru kapalı ve kalp atımı yokmuş. Kan basıncı alınamamış. Pupul ışık refleksi bilateral yokmuş. Hastaya 70 dakika 

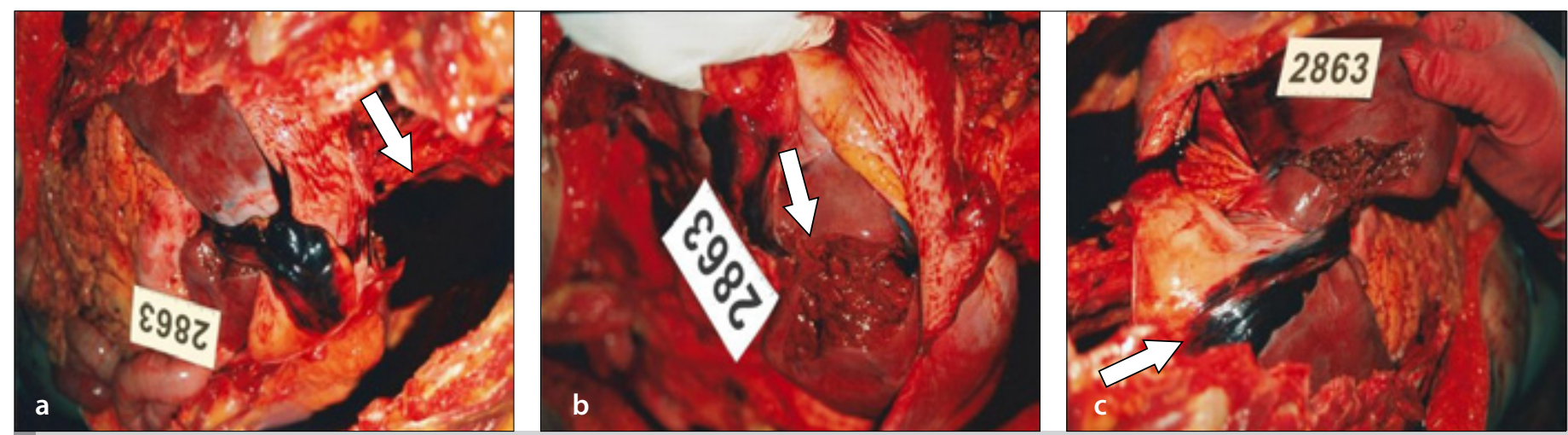

Resim 1. Batında kan koleksiyonu (a), karaciğer laserasyonu (b), ligamentum teres hepatitse hematom (c)

yapılan KPR'de göğüs kompresyonu manuel olarak yapılmış ve yanıt alınamayınca eksitus olarak kabul edilmiş.

Yapılan otopside dış muayene bulgularında; göğüs ön yüzde defibrilatör cihazına bağlı izler mevcuttu. İç muayenede; sternum kemiğinde 4. interkostal seviyede ekimozlu kırık tespit edildi. Her iki ana bronş ve özefagus lümenlerinde koyu kahverengi muhteva ve mayi varlığı gözlemlendi. Sol koroner arter inen ve dönen dalda lümeni orta derecede daraltıcı vasıfta aterom plakları ile sol inen dalın birinci santimetresindeki kesitlerde intralüminal trombüs parçacıkları olduğu ve daha sonra devam eden lümen kesitlerinin ise kısmen açık olduğu izlendi. Batından $1600 \mathrm{ml}$ serbest kan boşaltıldı(Resim 1a). Karaciğer ön yüz sağ lobda diafragmanın 1,5 $\mathrm{cm}$ altından başlayan ve alt keskin kenara dek inen $6 \times 2,5 \times 2 \mathrm{~cm}$ ebadında parankimal yırtık tespit edildi (Resim 1b). Ligamentum teres hepatis boylu boyunca derinliği $1 \mathrm{~cm}^{\prime}$ ye varan hematom varlığı görüldü (Resim 1c). Midede 200 ml koyu kahverengi gıda içeriği dışında otopsisinde başka anlamlı bulgu izlenmedi. Kan, idrar, mide içeriği alınarak sistematik toksikolojik analiz ve alkol taraması yapıldı; sonuçları ise negatif çıktı.

Adli Tıp Kurulu uzmanları bu denli yüksek miktardaki batın kanamasına KPR işlemi sırasında karaciğerde oluşmuş laserasyonun neden olabileceğini ve olgunun ani kalp krizi nedeniyle ölmüş olduğu yönünde ortak karara varmışlardır.

\section{Tartışma}

KPR hayat kurtarıcı olmakla beraber bir dizi invaziv uygulamaları nedeniyle pek çok komplikasyona neden olmakta ve bu komplikasyonların önemli bir kısmı göğüs kompresyonuna sekonder gelişmektedir (2).

Yüzde hemorajiler, retinal hemorajiler, subaraknoid hemorajiler, sternum ve kot fraktürleri, yağ embolisi, kardiyak rüptür, epikardiyal peteşi, myokardiyal hemoraji, mide, karaciğer, dalak, pankreas, bağırsak yaralanmaları göğüs kompresyonu ile ilişkili KPR komlikasyonlarıdır (2). Olgumuzda göğüs kompresyonu ile ilişkili olarak sternum fraktürü ve karaciğer yaralanması olmuştur.

Meron ve arkadaşları kardiyak arrest geçiren travmaya bağlı olmayan 2258 olgudan 15'inde majör karaciğer yaralanması olduğunu; 9' una yaşarken, 6' sına otopsi sırasında tanı konduğunu, sadece 2 hastanın yaşadığını belirtir (3). Olgumuzda KPR' ye yanıt alınamamış ve tanı otopside konulmuştur.

Sadece KPR'ye bağlı yaralanmaların olduğu bir çalışmada, 175 olgunun otopsi sonuçları retrospektif olarak incelenir. Manüel KPR sonucu bir olguda ligamentum falsiparuma yakın karaciğer orta hatta laserasyon saptanır. Mekanik KPR sonucu ise 3 olguda abdominal organ yaralanması görülür. Bu yaralanan organlardaki patolojiler; karaciğer sağ lob posterolateralde laserasyon, mezenterik laserasyon, splenik laserasyon ve hemoperitoneumdur (4). Başka bir çalışmada 47'si manüel, 38'i mekanik KPR' nin yapıldığı travmaya bağlı olmayan 85 olgunun otopsi sonuçları prospektif incelenir. Manüel KPR yapılanlarda karaciğer yaralanması saptanmazken, mekanik KPR yapılanlarda bir olguda karaciğer yaralanması saptanır (5). Bizim olgumuzda karaciğer yaralanması manüel KPR sonrası olmuştu. Karaciğerdeki yaralanma bulguları ise literatürle uyumlu bir şekilde karaciğer orta hatta lokalize idi.

Lau ve arkadaşları gebe bir bayanda KPR sonrası iatrojenik olarak abdominal kavitede 2000 ml kan ve karaciğer sağ lobda multipl laserasyonlar olduğunu belirtir (6). Bizim olgumuz gebe değildi ve KPR sonrası batın yaralanması literatürle benzerlik göstermekteydi.

KPR esnasında uygunsuz göğüs kompresyonu teknikleri nedeniyle karaciğer rüptürü olabilir. Göğüs kompresyonu sırasında ellerin göğüs üzerine yanlışyerleştirilmesi ile göğüs kompresyonu yapılması anatomik komşuluk nedeniyle karaciğerde ve diğer organlarda yaralanmaların meydana gelmesinde önemli bir neden olarak görülür (7). Uygun bir göğüs kompresyonunda kurtarıcı el ayasını kazazedenin göğsünün ortasına yerleştirmeli(sternumun alt yarısı), diğer elini birinci elin üstüne getirmeli, eller birbiri üstüne geçmeli ve paralel hale gelmelidir (1). Olgumuzda KPR sonrası karaciğer yaralanmasının olması uygun bir göğüs kompresyonu yapılmadığını düşündürmektedir.

Süresi uzayan KPR, komplikasyon oluşumunu etkiler. KPR süresi uzadıkça göğüs kompresyon kalitesi kötüleşir ve buna bağlı komplikasyon olasılığı artar $(8,9)$. Süresi uzayan KPR' ye bağlı intra abdominal komplikasyonlar meydana gelebilir (10). Olgumuzda karaciğer yaralanmasına etki eden bir faktörde uzamış KPR olabilir. 


\section{Sonuç}

KPR girişimleri hastalara uygulanan invaziv uygulamalar olup, beraberinde pek çok istenmeyen iatrojenik komplikasyonlar oluşturur. Uygun bir teknikle yapılmayan göğüs kompresyonları göğse anatomik komşuluğu nedeniyle karaciğer yaralanmasına neden olabilir. Bu nedenle uygulayıcıların KPR tekniklerini doğru bilmesi ve uygulamasının komplikasyonları azaltacağını düşünmekteyiz.

Hasta Onamı: Cumhuriyet savcısının emri ile adli otopsi yapıldığı için hasta onamı yoktur.

Hakem Değerlendirmesi: Dış bağımsız.

Yazar Katkıları: Fikir - E.Y., M.I.; Tasarım - M.Ö.; Denetleme - E.Ö.; Malzemeler - N.A.; Veri toplanması ve/veya işlemesi - E.Y., H.S.; Analiz ve/veya yorum - M.I., E.Y.; Literatür taraması - E.Y., M.I.; Yazıyı yazan M.I.; Eleştirel İnceleme - M.I.

Çıkar Çatışması: Yazarlar arasında herhangi bir çıkar çatışması yoktur.

Finansal Destek: Herhangi bir finansal destek alınmadı.

Informed Consent: There was not patient consent because forensic autopsy was applied by order of the prosecutor.

Peer review: Externally peer-reviewed.

Author Contributions: Concept - E.Y., M.I.; Design - M.Ö.; Supervision - E.Ö.; Materials - N.A.; Data Collection and/or Processing - E.Y., H.S.; Analysis and/or Interpretation - M.I., E.Y.; Literature Review - E.Y., M.I.; Writer - M.I.; Critical Review - M.I.

Conflict of Interest: The authors declared no conflict of interest.
Financial Disclosure: The authors declared that this study has received no financial support.

\section{Kaynaklar}

1. Cander B, Yıldııı A, Önalan O. Kardiyopulmoner resüsitasyon ve acil kardiyak bakım bilimi için 2010 Amerikan Kalp Derneği(AHA) KılavuzuIllk yardım için 2010 Amerikan Kalp Derneği(AHA) ve Amerikan Kızıl Haç Kılavuzu. In: Duran A, Kaya H, Akdur O. Erişkin temel yaşam desteği. 1. baskı. İstanbul: Logos Yayıncılık 2012; 81-121.

2. Hashimoto Y, Moriya F, Furumiya J. Forensic aspects of complications resulting from cardiopulmonary resuscitation. Legal Medicine 2007; 9: 9499 [CrossRef]

3. Meron G, Kurkciyan I, Sterz F, Susani M,Domanovits H, Tobler K, Bohdjalian A, Laggner AN. Cardiopulmonary resuscitation-associated major liver injury. Resuscitation 2007; 75: 445-53. [CrossRef]

4. Pinto DC, Pinneri KH, Love JC, Manual and Automated Cardiopulmonary Resuscitation (CPR): A Comparison of Associated Injury Patterns. J Forensic Sci 2013; 58: 94-9. [CrossRef]

5. Smekal D, Johansson J, Huzevkaa T, Rubertssona S. No difference in autopsy detected injuries in cardiac arrest patients treated with manual chest compressions compared with mechanical compressions with the LUCASTM device-A pilot study. Resuscitation 2009; 80: 1104-7 [CrossRef]

6. Lau G. A case of sudden maternal death associated with resuscitative liver injury. Forensic Sci Int 1994; 67: 127-32. [CrossRef]

7. Krischer JP, Fine EG, Davis JH, Nagel EL. Complications of Cardiac Resuscitation. Chest 1987; 92: 287-91. [CrossRef]

8. Dean JM, Koehler RC, Schleien CL, Berkowitz I, Michael JR, Atchison $D$, et al. Age-related effects of compression rate and duration in cardiopulmonary resuscitation. J Appl Physiol 1990; 68: 554-60.

9. -Hightower D, Thomas SH, Stone CK, Dunn K, March JA. Decay in quality of closed-chest compressions over time. Ann Emerg Med 1995; 26: 300-3. [CrossRef]

10. Bernard SA, Jones BM, Scott WJ. Intra-Abdominal Complications Following Prolonged Cardiopulmonary Resuscitation. Australian and New Zealand Journal of Surgery 1993; 63: 312-14. [CrossRef] 